METAgraphias: letra B de Belo (sobre belezuras baphônicas) v.1 n.3 setembrol2016

Corpo e alteridade em Gary Hill • Juliana Franco (judorf@gmail.com) \& Ana Lúcia Guimarães

\title{
corpo e alteridade em Gary Hill
}

\section{Resumo}

\section{Juliana Rocha Franco Ana Lúcia Oliveira Guimarães}

Este artigo busca compreender como se opera a produção de sentido desencadeada por obras de videoarte que reivindicam a participação do espectador, instaurando, assim, uma relação entre corpo, pensamento e alteridade. Especificamente serão trabalhadas duas obras do videoartista Gary Hill: "Inasmuch As It Is Always Already Taking Place" e "Tall Ships". Ao longo do trabalho duas questões são enfatizadas: na primeira, estuda-se a relação entre a videoarte e a construção da alteridade, numa reflexão sobre o lugar do outro na arte e na experiência estética; na segunda, trata-se de investigar como a dimensão de alteridade proporcionada pela videoarte nos leva a uma nova percepção do corpo, ou o movimento inverso, como novas percepções do corpo nos levam à dimensão de alteridade.

Palavras-chave: Videoarte; Corpo ; Alteridade

\section{Abstract}

This paper seeks to understand how it operates the production of meaning triggered by works of Video Art that claim the participation of the viewer, in a relationship between body, mind and otherness. Specifically, two works of video artist Gary Hill will be analyzed: "Inasmuch As It Is Always Already Taking Place" and "Tall Ships". Throughout the work the relationship between the Video Art and the construction of otherness is emphasized. The analysis take into consideration the place of the other in art and aesthetic experience and how the dimension of otherness provided by the Video Art leads us to a new perception of the body or the reverse movement, as new perceptions of the body can lead us to the dimension of otherness. 
Keywords: Video Art; Body; Otherness

Sim, existem sujeitos: são os grãos dançantes na poeira do visível, e lugares móveis num murmúrio anônimo. O sujeito é sempre um derivado. Ele nasce e se esvai na espessura do que se diz, do que se vê. (DELEUZE, 1992, p.134)

Ao longo do tempo, diferentes corpos foram criados por nossa cultura. O corpo em nosso trabalho é entendido como algo que não é somente um dado cultural, mas que se constrói no limite entre o biológico, o individual e o coletivo. A arte, segundo leda Tucherman (1999, p.16) pode ser compreendida enquanto produtora de um campo de experimentação que cria indagações e imagens do corpo. Apesar da acumulação e circulação incontrolável das imagens no mundo contemporâneo, Gary Hill não precisa de muitas imagens. Em suas obras - espectador não é submetido a imagens espetaculares, fusões e edições frenéticas características de um mundo midiático muitas vezes anestesiado pela hipertrofia das imagens. Neste trabalho, buscaremos apontar a relação entre duas videoinstalações de Gary Hill, o corpo e a construção da alteridade, numa reflexão sobre o lugar do outro, na arte e na experiência estética, proporcionada por obras que reivindicam a participação do espectador.

Em 1990, Hill produziu Inasmuch as It Is Always Already Taking Place (Figura 1) uma vídeoinstalação onde podemos observar um alto grau de fragmentação e multiplicação da imagem corporal. A instalação consiste em 16 monitores de dimensões variáveis, dos quais é removida a carcaça de plástico, espécie de caixa-preta que normalmente emoldura a tela e esconde as "entranhas" do circuito eletrônico. O conjunto dos monitores ocupa um vão na parede e está instalado em camadas, sendo que os monitores menores estão justapostos à frente e os maiores justapostos ao fundo. Esse trabalho exibe diferentes partes do corpo 
humano em tamanho real em cada um dos monitores: partes de um dorso, órgãos, membros desnudos.

Embora cada parte do corpo esteja em movimento e seja identificável, o arranjo dos monitores não segue a organização lógica e anatômica de um corpo humano. Assim, uma orelha e um pé ficam lado a lado. Atrás desses monitores está a imagem da virilha. A trilha sonora é formada por sons ambientes mixados a sons de partes do corpo sendo coçadas, respiração, uma língua estalando dentro da boca, som de ondas e murmúrios. Há também a imagem de uma barriga que se expande e se retrai com a respiração, um fragmento de face cujo recorte nos mostra um olho observador.

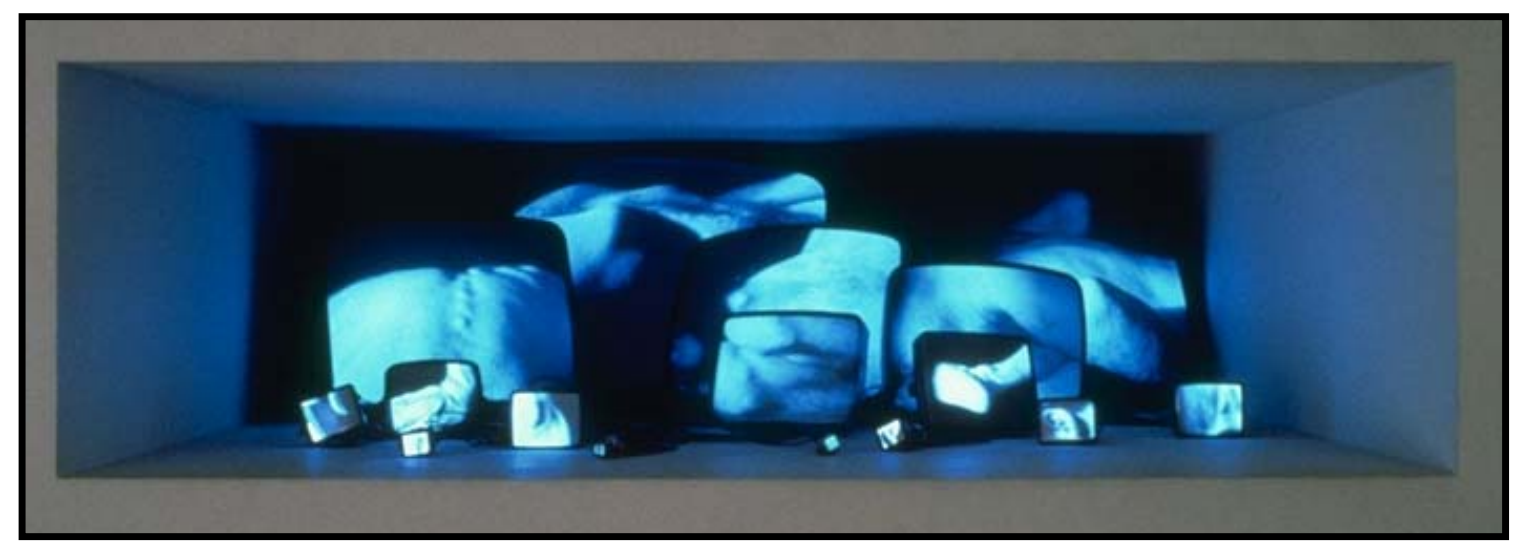

Figura 1 - Gary Hill - Inasmuch as It Is Always Already Taking Place. Disponível em: http://www.moma.org/collection/works/81321?locale=en

Se desde o Renascimento assinala-se a construção do indivíduo como fixo e soberano ${ }^{1}$,

\footnotetext{
${ }^{1} \mathrm{O}$ sujeito moderno, racional, centrado e unitário, na avaliação pós-estruturalista e pós-moderna, é uma construção muito particular do projeto iluminista que o pressupunha como capaz de opções racionais conscientes e autônomas em relação à
} 
resultando na concepção do sujeito do lluminismo como um indivíduo centrado, com identidade auto-suficiente, em Inasmuch as It Is Always Already Taking Place, ao contrário, Hill nos oferece um corpo fragmentado que reflete o caráter provisório e heterogêneo do processo de identificação contemporâneo, muitas vezes fragmentado, atravessadas por várias subjetividades e agenciamentos. Nesse sentido, é importante mencionar o conceito de "produção de subjetividade" (ou subjetivação) desenvolvido por Guattari (1992), e que visa ultrapassar o paradigma da noção substancial de identidade no pensamento moderno, que remonta ao cogito cartesiano: o eu como essência e unidade, fixo, essencialmente inato e inalterável a ideia de indivíduo como fixo e soberano.

Para Guattari (1992, p. 11), a subjetividade é enfatizada "enquanto produzida por instâncias individuais, coletivas e institucionais", enquanto construção subjetiva plural e polifônica, no sentido de Bakhtine. Essas características fazem da produção de subjetividade um processo complexo, em que interagem múltiplas vozes e forças produtivas, desde os contextos da família, da escola, do grupo social, até os meios técnicos de transmissão de valores e ideais, sendo transversalmente realizada por forças sociais, agenciamentos maquínicos, humanos e tecnológicos, em um processo intimamente ligado às interfaces de comunicação. Nesse sentido, o autor formula uma definição provisória e o mais englobante possível de subjetividade:

[...] o conjunto das condições que torna possivel que instâncias individuais e/ou coletivas estejam em posição de emergir como território existencial auto-referencial, em adjacência ou em relação de delimitação com uma alteridade ela mesma

sociedade, desde que devidamente educado. Isso o tornava peça fundamental na organização econômica e social dos estados modernos. Para o autor, a construção desta ideia de sujeito universal e atemporal só se tornou possível graças aos aparatos discursivos e linguísticos que, historicamente, o manufaturaram. Daí podermos entender a força com que a crítica pósestruturalista centrou seus argumentos na questão da linguagem. SILVA, Tomaz . Identidades Terminais: As Transformações na Política da Pedagogia e na Pedagogia da Política. Petrópolis: Vozes, 1996. p. 254-255) 
subjetiva. (GUATTARI, 1992, p.19)

A subjetivação aqui não é encarada como coisa em si, essência imutável: existe esta ou aquela subjetividade, dependendo de um agenciamento coletivo de enunciação produzi-la ou não. Por exemplo: o capitalismo moderno, através da mídia e dos equipamentos coletivos, produzem em grande escala um tipo de subjetividade que Guattari denomina subjetividade capitalistica.

Do mesmo modo que as máquinas sociais podem ser classificadas na rubrica geral de equipamentos coletivos de subjetivação, as máquinas tecnológicas de informação e de comunicação operam no núcleo da subjetividade humana, não apenas no seio de suas memórias, da sua inteligência, mas também de sua sensibilidade e seus afetos. (GUATTARI, 1992, p. 14)

Tal ideia de produção de subjetividade reitera a concepção polifônica de subjetividade, pois em vez de conceituar os indivíduos em si, com atributos substantivos essenciais, opta por defini-los em termos relacionais, uns em relação aos outros e em relação aos mais diversos agenciamentos produtores da subjetividade. Assim o conceito de produção de subjetividade (ou subjetivação) apreende o processo em que as identidades e as diferenças não se encontram já dadas, mas são formadas em condições práticas e articuladas através de discursos concretos em formas particulares de vida.

Dentre os agenciamentos produtores de subjetividade, é importante ressaltar o papel dos agenciamentos coletivos de mídia (os mass media) no processo de produção da subjetividade. Segundo Guattari (1992, p. 86), o modo de produção capitalístico funciona através de um controle da subjetivação, tendo a cultura de massa como motor da produção de subjetividade capitalística. Guattari concebe a subjetividade como produção, e considera que uma das principais características dessa produção nas sociedades "capitalísticas" seria, 
precisamente, a tendência a bloquear processos de singularização e instaurar processos de individualização:

Os homens, reduzidos à condição de suporte de valor, assistem, atônitos ao desmanchamento de seus modos de vida. Passam então a se organizar segundo padrões universais, que os serializam e os individualizam. Esvazia-se o caráter processual (para não dizer vital) de suas existências: pouco a pouco, eles vão se insensibilizando. A experiência deixa de funcionar como referência para a criação de modos de organização do cotidiano: interrompem-se os processos de singularização. (GUATTARI \& ROLNIK,1985, p. 38-39.)

Essa relação passiva do desejo constitui uma subjetividade consumidora, essencialmente serializada e padronizada. A subjetividade é permanentemente, incitada a assumir inconsciente ou mesmo semi ou conscientemente as representações de valores capitalísticos reificados dominantes. Essa padronização dos modos de sentir e subjetivar o mundo trabalha o tempo todo com a ilusão dos sentidos. O desejo é desinvestido de sua potência criadora. Assim o que teríamos é uma espécie de padrão corporal (mass media) a ser seguido. Contudo, em resposta à máquina de produção de subjetividade capitalística, Guattari e Rolnik propõem

A ideia de que é possível desenvolver modos de subjetivação singulares, aquilo que poderíamos chamar de "processos de singularização", uma maneira de recusar todos esses modos de encodificação preestabelecidos, todos esses modos de manipulação e de telecomando, recusá-los para construir, de certa forma, modos de sensibilidade, modos de relação com o outro, modos de produção, modos de criatividade que produzam uma subjetividade singular. (GUATTARI \& ROLNIK,1985, p. 16-17)

No caso de Inasmuch as It Is Always Already Taking Place, essa discussão é relevante na medida em que a padronização dos modos de subjetivação anulam a produção e/ou reconhecimento da alteridade: a relação eu/outro se torna cristalizada, sedimentada por concepções que já estão dadas. Torna-se, então, importante ressaltar que a construção de 
um corpo passa necessariamente pela construção de uma alteridade que faria limite e daria sentido a esse corpo.

Nesse contexto, o trabalho de Hill pode ser considerado uma instância de experimentação polifônica de regimes semióticos que podem funcionar como dispositivo atuante no núcleo de nossa subjetividade, modelando nosso pensamento e suscitando estados mentais que são correlatos a novas maneiras de sentir, conceber e conhecer. Em consonância com essa perspectiva, Domingues afirma que nas videoinstalações,

\footnotetext{
as verdades cartesianas das figurações escritas nos suportes matéricos cedem lugar aos processos microcelulares de dissipação e de regeneração. Os encontros e desencontros das figuras eletrônicas são avessos à inércia, ao imobilismo e contrariam a rigidez positivista de formas inteiras e fixas das imagens técnicas anteriores. 0 corpo como aparato sensorial entra num curto-circuito plurissensorial de "trompe les sens", onde sua modalidade analógica se funde a modalidades digitais. (DOMINGUES, 1995, p. 8)
}

Uma percepção contra-hegemônica dos corpos é um dos temas recorrentes do trabalho de Gary Hill, que pretende abalar fronteiras previamente estabelecidas entre o eu e o outro, o interior e o exterior, o subjetivo e o objetivo (Carvalho, 1994). Em Inasmuch as It Is Always Already Taking Place o que se observa é um deslocamento dessa imagem de corporeidade. O corpo é inserido dentro de diferentes tipos de espaço os quais são facilitados pela tecnologia eletrônica, onde a relação eu/outro é marcada pelo relacional em detrimento das cristalizações.

O corpo é fundamental para os mecanismos de identificação e alteridade. A alteridade pode aparecer de muitas formas. O corpo sustenta como matéria a produção dos processos de identificação a partir de suas evidentes marcas visuais que expõe a identidade do sujeito consigo mesmo e com a sociedade. Mas o corpo é também o limite que separa o sujeito ou 
o indivíduo do mundo e do outro, o lugar de onde se pode determinar a alteridade.

O outro serve para pensar a humanidade do homem como "natural" e necessária, pelo menos no percurso das nossas origens até os dias de hoje. (Tucherman,1999, p. 107-109). Quem é, portanto, o outro? É o que não deixa o mesmo enquanto mesmo repousar (Souza, 2000, p.59). Assim, pode-se afirmar que Hill expõe os fragmentos de um corpo outro de modo a confrontá-lo com a presença material do corpo do próprio espectador: a partir de um corpo fragmentado, o espectador pode localizar em si mesmo a presença de uma unidade corporal. Nos deparamos então com um corpo transformado, sem limites, voltando-se para a quebra da fronteira entre espécies e para os atritos entre orgânico/mecânico/eletrônico, produto de sua apropriação não como ideal do eu, miragem ou imagem, mas como presença, matéria moldável, suporte de escrita e de assinatura justamente quando este se desmaterializa no digital (Domingues, 1993, p.1994).

A imagem corporal é o primeiro esboço sobre o qual irão se desenhar, posteriormente, as identificações constitutivas da personalidade. A identidade que se produz no diálogo com Inasmuch as It Is Always Already Taking Place não é mais uma identidade centrada e unificada (Hall, 2014), mas "microidentificações" que vão se complexificando num processo fragmentado de instabilidade. A obra nos lança em espaços múltiplos, heterogêneos, fragmentados, avessos a pontos fixos de referência. O "espelho" que Hill nos oferece proporciona novos modos de existência e uma reconstituição do corpo a partir do fragmento. Ao invés de individuações pessoais criadas a partir do fragmento, surgem acontecimentos, no sentido (nietzscheano/deleuziano) de invenção de possibilidades de vida. Não tem contornos bem definidos e possui um caráter provisório e pontual, evanescente mesmo, em seus modos de configuração. 


\section{Tall Ships: eu é um outro}

Tall Ships (Figura 2) é uma instalação de Gary Hill, realizada em 1992, com projetores controlados por computador, instalados em um longo corredor. Ao entrar em Tall Ships, o que se percebe é um espaço de escuridão, e isso inicialmente desorienta o visitante. $\mathrm{Na}$ verdade, entramos em um corredor escuro e, conforme nossos olhos se acostumavam com a penumbra, começamos a perceber vultos ao redor caminhando em nossa direção. São projeções nas duas paredes que mostram imagens de pessoas que se aproximam e se afastam, acionadas pela presença do espectador. É ele quem estabelece a comunicação com o trabalho ao caminhar nesse espaço.

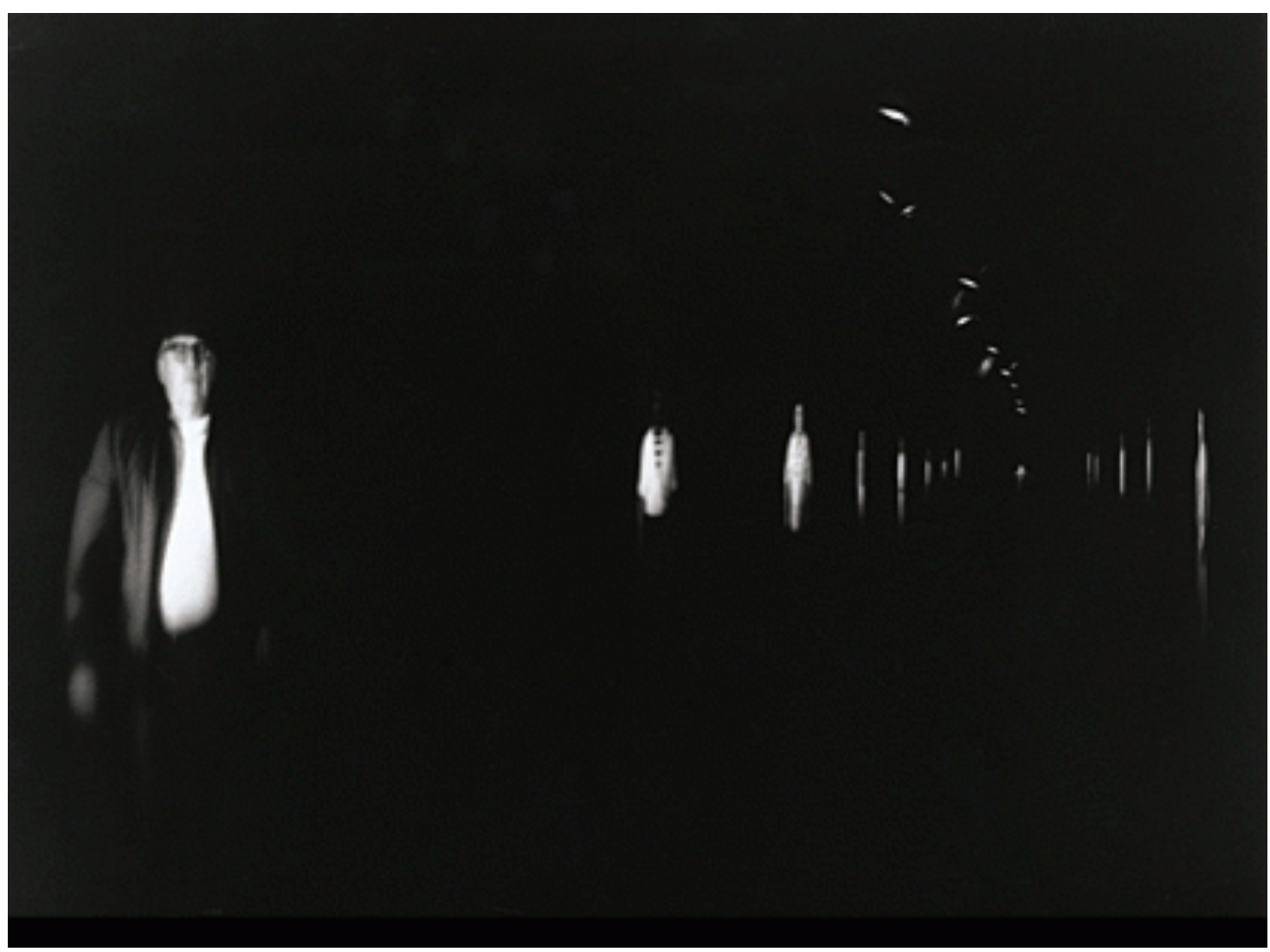

Figura 2. Tall Ships. Disponível em: http://dig.henryart.org/northwest-artists/assets/images/artworkimages/cccdd8b9ca0bc06acee117f9cf0ef4da.jpg 
Conforme afirma Carvalho (1994, p.1), "a ilusão dessa proximidade difusa faz com que o espectador estabeleça uma relação especular, sem entender a princípio se aquelas imagens eram reflexos de si mesmo ou de outras pessoas, se eram pessoas reais ou outros espectadores que talvez estejam na sala, a seu lado". O espaço do sentido não preexiste à instalação, sendo forjado ao longo de seu percurso, através dos encontros sucessivos entre o espectador e as personagens de luz da instalação. O que está em jogo, para Gary Hill, é a construção sempre inacabada e provisória de nós mesmos a partir do encontro com o outro, desde que se entenda que é sempre a partir de nosso poder de afetar e ser afetado, no aqui-agora, que consideramos o corpus de imagens que compõe Tall Ships. Tal perspectiva é assumida na esteira da retomada do pensamento de Espinosa por Deleuze e Guattari (1997, p. 42), os quais, ao invés de definir um corpo por seus órgãos, funções, Espécie ou Gênero, preferem "enumerar seus afectos":

Os afectos são devires. Espinosa pergunta: o que pode um corpo? [...] Não sabemos nada de um corpo enquanto não sabemos o que pode ele, isto é, quais são seus afectos, como eles podem ou não compor-se com outros afectos, com os afectos de outro corpo, seja para destruí-lo ou ser destruído por ele, seja para trocar com esse corpo ações e paixões, seja para compor com ele um corpo mais potente." (DELEUZE; GUATTARI, 1997, p. 42-43).

Com efeito, retomando uma formulação que Peter Pál Pelbart realizou em outro contexto, pode-se afirmar que a vídeoinstalação de Gary Hill mobiliza poeticamente a coisa mais comum do mundo: "a dor no encontro com a exterioridade", sinal/ marca/ traço de nossa "condição de corpo afetado pelas forças do mundo" (Pelbart, 2003, p. 42-45). Tudo começa, portanto, através dos encontros entre os corpos, encontros nos quais os corpos interagem e se afetam uns aos outros, trocando ações e paixões. Nesse sentido, todo corpo 
só pode ser entendido como relação, ele mesmo só se forma em função dos encontros nos quais se envolve.

Deleuze insiste: um corpo não cessa de ser submetido aos encontros, com a luz, o oxigênio, os alimentos, os sons e as palavras cortantes - um corpo é primeiramente encontro com outros corpos." (PELBART, 2003, p.46)

Em Tall Ships, o corredor escuro cria uma espacialidade, uma ambientação que enfatiza a dimensão de encontro entre o corpo do espectador e o corpo das personagens luminosas. Para pensar a espacialidade propícia aos encontros entre corpos, vale retomar a distinção que Michel de Certeau (1995, p. 201) estabelece entre espaço e lugar. Para ele, lugar é uma ordem segundo a qual se distribuem elementos nas relações de coexistência, uma configuração instantânea de posições, enquanto o espaço é animado pelo conjunto de movimentos que se desdobram no lugar. "O espaço é um lugar praticado" (Certeau, 1995, p.202), produto das relações humanas, tecido por relações que se realizam no plano do vivido, o que garante a construção de uma rede de significados onde sentidos são tecidos.

A partir da dinâmica de encontros entre o espectador e as personagens de luz que se apresentam no percurso da vídeoinstalação, podemos dizer que Tall Ships, ao funcionar como um campo projetivo da experiência humana, torna-se espaço vivido ou "lugar praticado", no sentido da expressão de Michel de Certeau. A obra de Hill cria situações de experiência estética que permitem o reconhecimento de nós mesmos através da imagem do outro, numa investigação destinada a convocar a subjetividade do espectador à afecção de ser contaminada pela alteridade do objeto estético, alteridade através do qual o homem pode se corporificar no espaço (Carvalho, 1994). Dessa maneira, a transformação de lugar em espaço vivido (ou " lugar praticado") aponta para a necessidade de considerar o corpo. É por meio dele que o homem se apropria do espaço (através de modos de uso). Para Perec 
(apud CARLOS, 1996, p.78), é o corpo que dá acesso ao mundo.

Entretanto, esse corpo outro já não é um corpo orgânico, nem um invólucro de uma suposta interioridade imaginária que constituiria a unidade de de um eu (Rolnik 1993, p.106). Se conforme afirmam Deleuze e Guattari (2004, p. 9-29) , o organismo é uma leitura possível do corpo e parte da ideia de que, por dentro, obedecemos a uma organização, "um estrato que bloqueia os fluxos e nos fixa neste nosso mundo", Rolnik $(1993$, p.107) nos apresenta a existência de um " corpo vibrátil", corpo que é um foco de resistência ao organismo. O "corpo vibrátil é o corpo não fragmentado, é aquele que alcança sentir, perceber, "ver" o que para o outro corpo (esse, que estamos "acostumados" a ter, a conhecer e a usar para apreender o que está à nossa volta) é invisível (Rolnik, 1993, p. 106-110).

Em Tall Ships, a relação do corpo com o espaço cria uma percepção diferenciada do corpo: a percepção do outro, do corpo do outro que se torna reativo ao nosso, a corporificação de um novo feixe de sensações, singular por definição. Isso possibilita a constituição de novos modos de subjetivação: "indivíduo-máquina", trocas múltiplas, que oferecem à pessoa possibilidades diversificadas de recompor uma corporeidade existencial, "sair de seus impasses repetitivos e, de alguma forma se re-singularizar" (Guattari, 1992, p.17). Multiplicidade, complexidade, multimediação; o jogo com as possibilidades perceptivas em "Tall Ships" pode secretar novos modos de existência, eus, "corpos, como acontecimentos, como aquilo que sempre está por aparecer, por ser produzido" (Rolnik, 1993, 107), devir, sempre inacabado, sempre a fazer-se, que extravasa toda a matéria vivível ou vivida. É como afirma Deleuze (1997, p. 11) um processo, quer dizer, uma passagem de vida que atravessa o vivível e o vivido, no qual podem surgir condições para: 
águas instáveis do corpo aformal e adquirir a liberdade de fazer outras dobras, toda vez que um novo feixe de sensações assim o exigir, resgatar a vida em sua potência criadora, seja qual for o terreno em que se exerça tal potência. (ROLNIK, 1993, p.05).

O movimento de subjetivação incorpora um processo de alteração, assim como o reconhecimento da alteridade onde emerge a auto-consciência do sujeito. A interlocução possível é a "que se dá aos tropeços, fraturando sentidos e sujeitos, onde a compreensão é um desafio e uma aposta. O outro não funciona como espelho da identidade (num esquema representacionista), mas como pontuação múltipla e polissêmica do discurso alter-dirigido" (Soares, 1994, p. 168). Ao tensionar a subjetividade até pluralizá-la, Tall Ships abala fronteiras previamente estabelecidas entre o eu e o outro, o interior e o exterior, o subjetivo e o objetivo.

\section{REFERÊNCIAS}

CARLOS, A.F.A. O lugar no/do mundo. São Paulo: Hucitec, 1996

CARVALHO, Bernardo. Gary Hill exibe a imagem mental. Folha de São Paulo/llustrada, 22/Fev/94.

CERTEAU, Michel. A invenção do cotidiano. Petrópolis: Vozes, 1995

DELEUZE, Gilles. Conversações. Rio de Janeiro: Ed.34, 1992.

DELEUZE, Gilles. Crítica e clínica. São Paulo: Ed. 34, 1997.

DELEUZE, G.; GUATTARI, F. Mil Platôs: capitalismo e esquizofreni V.3. Rio de Janeiro: Editora 34, 2004.

DOMINGUES, Diana. O Sentir Eletrônico e a Estética da Metamorfose. In: LAZZAROTTO. Valentim A. (Org.). Teoria da ciência: diálogo com cientistas. Simpósio Nacional sobre Teoria da Ciência. Maio - Junho, 1995. Caxias do Sul: $1996 . \quad$ Disponível em: https://www.academia.edu/501168/O sentir eletrônico ea estética da metamorfose> Acesso em 5/2016.

GUATTARI, Félix. Caosmose. Um novo paradigma estético. RJ: Ed34, 1992.

GUATTARI \& ROLNIK, Suely. Micropolítica. Cartografias do Desejo. Petrópolis: Vozes, 1985.

PELBART, Peter Pál. Vida capital. São Paulo: Iluminuras, 2003. 
ROLNIK, Suely. Ligia Clark e a produção de um estado de arte .in: revista imagens n4 , 1993.

. "Fale com ele" ou como tratar o corpo vibrátil em coma. In: FONSECA, T. G.; ENGELMAN, S. (Org.). Corpo, arte e clínica. Porto Alegre: UFRGS, 2004a. p. 33-45.

SILVA, Tomaz . Identidades Terminais: As Transformações na Política da Pedagogia e na Pedagogia da Política. Petrópolis: Vozes, 1996.

SOARES, Luiz Eduardo. O rigor da disciplina. Rio de Janeiro: Relume Dumará, 1994.

SOUZA, R. T. Fulcro da história, urgência do pensamento - sobre a compreensão do conjunto da obra de E. Levinas - um breve estudo introdutório. in: SOUZA, R. T. Sentido e Alteridade-dez ensaios sobre o pensamento de E. Levinas, Porto Alegre: EDIPUCRS, 2000.

TUCHERMAN, leda. Breve história do corpo e de seus monstros. Lisboa: Ed. Veja, 1999. 